\title{
Social Intelligence and Its Relationship with School Administrators' Knowledge Absorption Capability
}

\section{Moazameh Nouri}

Associate Professor, Department of Educational Sciences, Faculty of Educational Sciences and Psychology, University of Sistan and Baluchestan, Zahedan, Iran

\begin{abstract}
Abdul Wahab Pourghaz
Associate Professor, Department of Educational Sciences, Faculty of Educational Sciences and Psychology, University of Sistan and Baluchestan, Zahedan, Iran Corresponding Author Email: w.pourghaz@ped.usb.ac.ir
\end{abstract}

Hossein Jenaabadi

M.A. Student of Educational Administration, Department of Educational Sciences and Psychology, University of Sistan and Baluchestan, Zahedan, Iran

\section{Doi:10.5901/mjss.2015.v6n6s6p333}

\section{Abstract}

The main objective of this study was to investigate administrators' social intelligence and its relationship with knowledge absorption capability in Zahedan middle and high schools. This was a descriptive-correlational research. The population of the study consisted of all administrators $(N=80)$ of girls' middle and high schools in Zahedan. Among the questionnaires which were distributed, 68 copies were returned and then analyzed. In this study, Tromso's Social Intelligence Questionnaire (2001), consisting of 21 items, and Knowledge absorption Inventory adopted from Sa'adatmand (2008) with 31 items were used. Face and content validity of the questionnaires was checked. Their reliability was estimated using Cronbach's alpha coefficient which was 0.87 and 0.94 , respectively. Regarding the descriptive statistics, mean and standard deviation were used. For inferential data analysis, statistical tests including the Pearson correlation coefficient, regression analysis, independent $t$-test and onesample t-test were applied. Findings suggested the desirability of social intelligence and knowledge absorption capability from administrators' perspective. Moreover, a significant relationship was observed between social intelligence and ability to absorb knowledge. By investigating the dimensions of social intelligence in predicting administrators' knowledge absorption capability, it was revealed that first social information processing and then social skills were best predictors of the ability to absorb knowledge. In addition, administrators' social intelligence and knowledge absorption capability accorded with their field of study as well as educational level.

Keywords: Social Intelligence, Knowledge Absorption Capability, Administrators of Girls' Schools, Middle and High Schools

\section{Introduction}

Management and education management experts have considered various dimensions for educational administrators' skills and offered a set of features- not one- for administrators toward more success. Among the features, capabilities, knowledge and skills of school administrators, the following could be mentioned: mental health, emotional health, sanity, power of perception, thinking, faith, piety and self-management, general and specialized knowledge, experience, appropriate morality and attitude, talent and leadership and management capabilities including intelligence (Safi, 2001: 40-42).

Social intelligence is one of the traits considered for administrators. Administrators with higher social intelligence can help and accelerate educational organizations to achieve their educational goals and due to developments in the field of information and communication technologies which promote a new lifestyle, a new era has emerged that is called the information age or the knowledge era (Beykzadeh \& Dudmani Maleki, 2011: 650).

In this era, knowledge is an irreplaceable source and the goal should always be realization and development of intellectual capital. Since the most valuable asset of any organization is its human resources, organizations are able to survive in today's world, which are able to continuously adapt to the changing environment. Such a changing environment 
will not ever allow organizations to be traditionally managed against pressures arising from the rivals' skills, capabilities and technologies. Organizations are forced to continually adapt to the environment to pursue best practices and procedures. One way to achieve success is to emphasize on learning and knowledge absorption capability to achieve organizational goals with maximum effectiveness (Sobhaninejad, 2006: 23).

Therefore, today's organizations need to create, store and use new knowledge as one of the most important determinants of growth and development. Absorption capacity is introduced as an important factor in the application of new knowledge. Since the major institutions of a society are educational organizations, doubled attention to human resources, skilled specialists and particularly administrators of educational institutions will be associated with their peak success, growth and reputation paving the way to arouse public trust.

Educational organizations are dynamic and constructive, if they connect and interact with their external environment. Social interactions are established both among the members of the organization and among the educational organization and other organizations. What is important is that the success of these multilateral interactions which refers to the successful performance of the organization's director. Most scholars agree that in addition to cognitive skills important interpersonal skills such as motivation, administrators need to have mutual interactions. What is less regarded in such skills is the proper application of these skills that are needed for a full understanding of a social group. Such an understanding of a social milieu refers to social intelligence. Social intelligence is a key factor of perception and recognition within the interpersonal scope (Boal \& Hooijberg, 2000: 520).

Among the management styles, managing the education agencies is known of the highest important knowledge of the time. Educational administrators play a critical role in advancing the goals of education. Management and education management experts have raised various dimensions for educational administrators' skills and offered a set of featuresnot one- for administrators toward more success. Among the features, capabilities, knowledge and skills of school administrators, intelligence and general and specialized knowledge could be mentioned (Safi, 2001: 40-42).

One way to achieve success is to highlight learning and knowledge absorption capability to accomplish organizational goals with maximum efficiency (Sobhaninejad, 2006: 23). Knowledge absorption capability has been raised as one of the main factors in applying the new knowledge. Since one of the major institutions of society are educational organizations, doubled attention to human resources, skilled experts and particularly administrators of educational institutions will be associated with their success paving the way to provoke public reliance.

If administrators have the ability to absorb knowledge, they can improve their own performance. Dictated solutions cannot meet today's complex world. It is essential that administrators invent new solutions and act innovatively in the face of unforeseen obstacles. The first component of innovation is the acquisition of knowledge. Administrators should become familiar with the new and updated knowledge and swim in the information flow. This is called knowledge absorption capability (Sa'adatmand, 2008: 4). Shaker and Gerard (2002) have defined the knowledge absorption capability as a set of procedures and processes including acquisition, assimilation, transformation and application of knowledge to create a dynamic capability for the organization (Comison \& Fores, 2010: 708)

Social intelligence should be able to provide the art of coping with negotiations, conflicts and mistakes. All sections of the society, especially administrators, need social intelligence. School administrators have the highest relationship at the technical level. They are the link between the society, the school and the education system. Thus, school administrators are required to have high social intelligence to play a more effective role in their communication (Rezaei \& Khalilzadeh, 2009: 125). In today's world, administrators always face new and unforeseen situations which the requirement to deal with is applying new and updated knowledge. Given the importance and sensitivity of the intersection between education management and the intersection of the field of psychology and management sciences in this area, research of this kind can create new management styles. High ability to absorb knowledge is able to fill the gaps in the structure of the innovation system (Uotila, 2006: 53). Therefore, administrators' intelligence, including social intelligence and ability to absorb knowledge, is an important factor for the development and increase the efficiency and effectiveness of the organization. It seems that to survive and function, educational organizations and schools require administrators with deeper social intelligence to be able to carry out their functions effectively. Having high social intelligence is one of the most important factors in building relationships with others. In this regards, this study sought to answer the question that whether or not there is a relationship between social intelligence of administrators and their capability to absorb knowledge in girls' middle and high schools in Zahedan.

To meet the research objectives, the following questions were posed:

1. How is the state of social intelligence from girls' middle and high schools administrators' point of view?

2. How is the state of knowledge absorption capability from girls' middle and high schools administrators' point of view?

3. Is there any relationship between social intelligence of administrators and their capability to absorb 
knowledge?

4. Are dimensions of social intelligence able to predict administrators' capability to absorb knowledge?

5. Do administrators' social intelligence and capability to absorb knowledge significantly vary according to their field of study?

6. Do administrators' social intelligence and capability to absorb knowledge vary significantly according to their educational level?

\section{Literature Review}

Tromso's social intelligence model includes three dimensions: social information processing, social skills and social awareness that help understanding of the social behavior of individuals, including administrators, in various situations (Beheshtifar \& Roasayi, 2012, as cited in Deng et al., 2008).

Social information processing refers to the ability to understand and predict behavior and feelings of others and social skills refers to behavioral aspects of the social intelligence construct through assessing the ability to enter into new situations and social adaption ability and social awareness assesses unexpected currents of events in social situations (Gini, 2006: 308).

Knowledge acquisition refers to the ability to recognize and seize the knowledge. Knowledge internalization refers to the ability to analyze, process, interpret and understand updated information of external sources. Knowledge transform refers to the ability to develop and restructure current activities which facilitate the process of combining existing knowledge with new and internalized knowledge and knowledge application refers to the ability to regularly integrate knowledge in operations and organizational goals (Rahmani \& Mousavi, 2011: 432).

Regarding social intelligence and capability to absorb knowledge, Sa'adatmand (2008) concluded that there is a significant relationship between social intelligence and capability to absorb knowledge. Oslub (2010), examining the relationship between social intelligence and capability to absorb knowledge among administrators in Boukan, found that social intelligence and capability to absorb knowledge are significantly and positively correlated. Among the research relevant to this case, the following can be cited: Yahyazadeh, et al. (2012) examined the impact of social intelligence of high school teachers on classroom discipline strategies in Salango, Malaysia. The results indicated a significant difference between teachers with high and medium levels of social intelligence and discipline strategies, and also demonstrated a significant difference between social intelligence of teachers with different races.

Yahyazadeh and Goudarzi (2012) investigated the relationship between social intelligence and personality traits among middle school teachers. The results suggested that there was a significant difference between social intelligence and age difference and also demonstrated that there was a significant positive relationship between their social intelligence and personality traits. Hooda et al. (2009) examined social intelligence as a predictor of positive mental health and indicated that social intelligence significantly predicts dimensions of mental health. Deng et al., (2008) explored the relationship of absorption capability with innovation/production among engineers working in the information technology section. The relationship between the ability to absorb people through the development of information technology for problem solving and decision-making to innovative products was surveyed among 208 engineers who used computers. The results suggested that the ability to absorb knowledge had a positive and significant effect on the performance of engineers. Kotabe, et al, (2011), examining the management relations, knowledge acquisition, potential absorption capability and new performance in emerging multinational corporations, a case study in China, concluded that the acquisition of knowledge and its application improves corporate performance.

Lenox and King (2004), in an article entitled investigating the landscape of absorption capability through the provision of internal information, concluded that absorption capability facilitated useful activities. Managers develop absorption capability by creating internal networks to provide information.

Experts proposed several scales in the field of social intelligence so that some of the scales focused on cognitive aspects that later developed into scales based on others' evaluation and interpretation, interpretation of photos and videos and the like. Due to disagreement and lack of correlation between the components and considering the fact that some methods are difficult and time-consuming, Silvera, Martinussen and Dahl (2001) to overcome these limitations stated that Tromso's Social Intelligence Scale measures three different aspects: social information processing, social skills and social awareness (Rezaei, 2010).

Cohen and Levintal stated that the ability to absorb knowledge has three dimensions including acquisition, internalization and application/use. Uotila (2006) and Shaker and Gerard (2002) had a closer look at different components of knowledge absorption, including acquisition, assimilation, and application. In the present study, the theoretical model of Tromso social intelligence (independent variable) and knowledge absorption capability by Shaker 
and Gerard (dependent variable) was used.

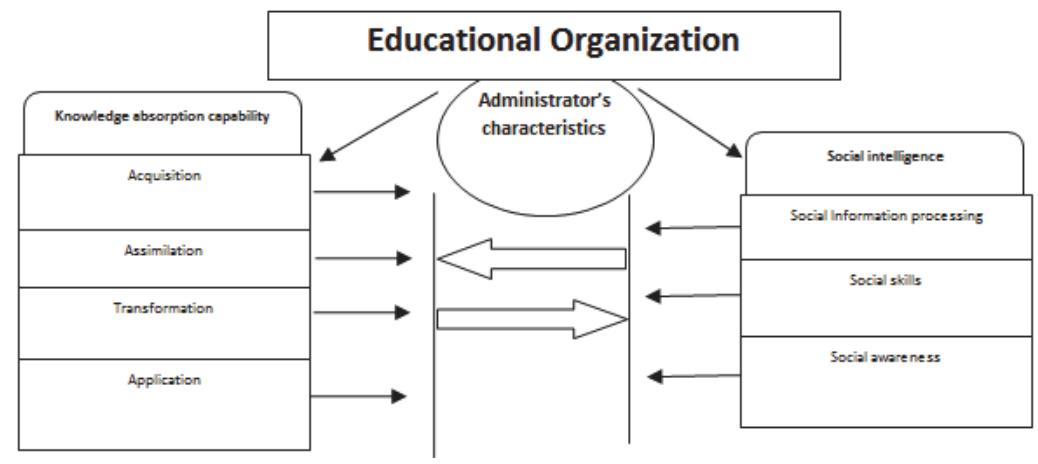

Figure (2-1): The theoretical framework of the research

\section{Methods and Materials}

The descriptive-correlational research method was used. The population of the study included all 80 girls' middle and high school administrators in Zahedan in the academic year of 2012-2013. In Morgan's table, the sample size of a population of 80 subjects is 66 . Given that there was not much difference between the population and samples, the whole population was studied. However, some schools did not cooperate. A number of incomplete questionnaires were excluded (12 questionnaires) and analysis was conducted on 68 copies.

To collect data, two questionnaires were used:

1. Social Intelligence Inventory: To measure the administrators' social intelligence, Tromso's (2001) questionnaire was used. It consists of 21 items and three dimensions including social information processing (8 items), social skills ( 6 items) and social awareness (7 items).

2. Knowledge Absorption Capability questionnaire: To assess the administrators' ability to absorb knowledge, a researcher-made questionnaire was developed based on Sa'adatmand's (2008) inventory. The questionnaire consisted of 31 items and four dimensions including acquisition (8 items), internalization (13 items), transformation (6 items) and application (4 items).

Both instruments were designed based on a 5-point Likert scale including completely agree (5 points), agree (3 points), partially agree (2 points), disagree (2 points) and completely disagree (1 point).

The number of items for each dimensions and their reliability are represented in the following tables.

Table 1: Social intelligence, frequency of items and reliability coefficients of its components

\begin{tabular}{|l|l|l|c|c|c|}
\hline & Component & items & frequency of items & Alpha & N \\
\hline $\mathbf{1}$ & Social information processing & $1-2-3-4-5-6-7-8$ & 8 & 0.86 & 25 \\
\hline $\mathbf{2}$ & Social Skills & $9-10-11-12-13-14$ & 6 & 0.84 & 25 \\
\hline $\mathbf{3}$ & Social Awareness & $15-16-17-18-19-20-21$ & 7 & 0.80 & 25 \\
\hline $\mathbf{4}$ & Social Intelligence (total) & & 21 & 0.87 & 25 \\
\hline
\end{tabular}

Table 2: Knowledge absorption capability, frequency of items and reliability coefficients of its components

\begin{tabular}{|l|l|l|c|c|c|}
\hline & Component & Items & frequency of items & Alpha & N \\
\hline $\mathbf{1}$ & Acquisition & $1-2-3-4-5-6-7-8$ & 8 & 0.85 & 25 \\
\hline $\mathbf{2}$ & Internalization & $9-10-11-12-13-14-15-16-17-18-19-20-21$ & 13 & 0.78 & 25 \\
\hline $\mathbf{3}$ & Transformation & $22-23-24-25-26-27$ & 6 & 0.89 & 25 \\
\hline $\mathbf{4}$ & Application & $28-29-30-31$ & 4 & 0.85 & 25 \\
\hline $\mathbf{5}$ & Absorption capability & & 31 & 0.94 & 25 \\
\hline
\end{tabular}


For data analysis, regarding the descriptive statistics, mean and standard deviation were used and to test the research hypotheses, inferential data analysis statistical tests including the Pearson correlation coefficient, regression analysis, independent t-test and one-sample t-test were applied.

\section{Results}

\subsection{Q1: How is the state of social intelligence from girls' middle and high schools administrators' point of view?}

To answer this question, one-sample t-test was used. The results are presented in Table 3.

Table 3: Results of one-sample t-test in relation to administrators' social intelligence

\begin{tabular}{|l|c|c|c|c|c|c|}
\hline Component & Mean & SD & Test value & t & df & Sig \\
\hline Social information processing & 29.26 & $4.66 / 4$ & 24 & 9.31 & 67 & 0.000 \\
\hline Social Skills & 20.92 & 23.3 & 18 & 7.46 & 67 & 0.000 \\
\hline Social Awareness & 23.33 & 26.4 & 21 & 4.51 & 67 & 0.000 \\
\hline Social Intelligence (total) & 73.52 & 9.31 & 63 & 9.32 & 67 & 0.000 \\
\hline
\end{tabular}

The results in Table 3 show that the mean value of social intelligence is 73.52 , which is greater than the test value (63). The difference is significant at the $99 \%$ confidence level $(t=9.32, \mathrm{df}=67, \mathrm{p}<0.01)$. Additionally, the mean value of the components of social intelligence including social information processing $(M=29.26, t=9.31)$, social skills $(M=20.92$, $t=7.46)$ and social awareness $(M=23.33, t=4.51)$ are greater than the test values (24, 18, and 21 respectively). The differences are significant at the $99 \%$ confidence level $(p<0.01)$, which indicates the desirability of social intelligence and its dimensions from the perspective of school administrators.

\subsection{Q2: How is the state of knowledge absorption capability from girls' middle and high schools administrators' point of} view?

To answer this question, one-sample t-test was used. The results are presented in Table 4.

Table 4: Results of one-sample t-test in relation to administrators' knowledge absorption capability

\begin{tabular}{|l|c|c|c|c|c|c|}
\hline Component & Mean & SD & Test value & $\mathbf{t}$ & df & Sig \\
\hline Acquisition & 30.44 & 3.16 & 24 & 16.76 & 67 & 0.000 \\
\hline Internalization & 52.77 & 6.6 & 39 & 17.21 & 67 & 0.000 \\
\hline Transformation & 26.39 & 3.67 & 18 & 18.85 & 67 & 0.000 \\
\hline Application & 17.33 & 2.35 & 12 & 18.7 & 67 & 0.000 \\
\hline Absorption capability & 126.95 & 14.03 & 93 & 19.95 & 67 & 0.000 \\
\hline
\end{tabular}

The results in Table 4 show that the mean value of absorption capability is 126.95 , which is greater than the test value (93). The difference is significant at the $99 \%$ confidence level ( $t=19.95, \mathrm{df}=67, \mathrm{p}<0.01)$. Additionally, the mean value of the components of absorption capability including acquisition $(M=52.77, t=17.21)$, internalization $(M=26.39, t=18.85)$, transformation $(M=26.39, t=18.85)$, and application $(M=17.33, t=18.7)$ are greater than the test values $(24,39,18$ and 12 respectively). The differences are significant at the $99 \%$ confidence level $(p<0.01)$, which indicates the desirability of knowledge absorption capability and its dimensions from the perspective of school administrators.

\subsection{Q3: Is there any relationship between social intelligence of administrators and their capability to absorb} knowledge?

To answer this question, the Pearson correlation coefficient was used. The results are presented in Table 5. 
Table 5: Results of the Pearson correlation between social intelligence and knowledge absorption capability

\begin{tabular}{|c|c|c|c|c|c|}
\hline Variable & Acquisition & Internalization & Transformation & Application & Absorption capability \\
\hline Information Processing Social & $=0 / 519 * * r$ & $=0 / 532 * * r$ & $=0 / 563 * * r$ & $=0 / 509 * * r$ & $=0 / 600 * * r$ \\
\hline Social Skills & $=0 / 351 * * r$ & $=0 / 424 * * r$ & $=0 / 437 * * r$ & $=0 / 429 * * r$ & $=0 / 465 * * r$ \\
\hline Social Awareness & $=0 / 275^{* * r}$ & $=0 / 360 * r$ & $=0 / 302 * * r$ & $=0 / 241 * * r$ & $=0 / 351 * r$ \\
\hline Total (social intelligence) & $=0 / 507 * r$ & $=0 / 578 * r$ & $=0 / 572 * * r$ & $=0 / 514 * * r$ & $=0 / 623 * r$ \\
\hline
\end{tabular}

The results in Table 5 indicate that the correlation between social information processing and components of acquisition $(r=0.519)$, internalization ( $r=0.532)$, transformation $(r=0.563)$, application $(r=0.509)$ and knowledge absorption capability $(r=0.6)$ is positive and significant at the $99 \%$ level $(p<0.01)$.

The correlation between social skills and components acquisition $(r=0.351)$, internalization $(r=0.424)$, transformation ( $r=0.437)$, application $(r=0.429)$ and knowledge absorption capability $(r=0.465)$ is positive and significant at the $99 \%$ level $(p<0.01)$.

The results in Table 5 indicates that the correlation between social awareness and components acquisition ( $r=$ $0.275)$, transformation $(r=0.302)$, application $(r=0.241)$ is positive and significant at the $95 \%$ level $(p<0.05)$. However, the correlation between social awareness and internalization $(r=0.36)$, and knowledge absorption capability $(r=0.351)$ is positive and significant at the $99 \%$ level $(p<0.01)$.

The correlation between social intelligence and acquisition ( $r=0.507)$, internalization $(r=0.578)$, transformation $(r=0.572)$, application $(r=0.514)$ and knowledge absorption capability $(r=0.623)$ is positive and significant at the $99 \%$ level $(p<0.01)$.

\subsection{Q4: Are dimensions of social intelligence able to predict administrators' capability to absorb knowledge?}

To answer the question, stepwise regression was used. The results are presented in Table 6.

Table 6: Results of regression in relation to predictive power

\begin{tabular}{|c|l|c|c|c|c|c|c|}
\hline Step & \multicolumn{1}{|c|}{ Variable } & R & Adjusted R & F & Standardized B & T & Sig \\
\hline $\mathbf{1}$ & Social information processing & 0.60 & 0.36 & 37.09 & 0.60 & 6.09 & 0.000 \\
\hline 2 & $\begin{array}{l}\text { Social information processing } \\
\text { Social Skills }\end{array}$ & 0.64 & 0.4 & 22.52 & 0.49 & 4.60 & 0.000 \\
& & & & 0.25 & 2.33 & \\
\hline
\end{tabular}

The results in Table 6 indicate that, in the first step, social information processing is a better predictor of knowledge absorption capability compared to other variables. This variable alone can predict $36 \%$ of the variations in administrators' knowledge absorption capability. In the second step, social skills entered the prediction model and these two variables are able to predict $40 \%$ of the variations in administrators' knowledge absorption capability. This means that social skills alone can predict $4 \%$ of the variation.

\subsection{Q5: Do administrators' social intelligence and capability to absorb knowledge significantly vary according to their} field of study?

To answer the question, independent t-test was used. The results are presented in Table 7.

Table 7: Results of independent t-test comparing administrators' social intelligence and knowledge absorption capability with regard to their field of study

\begin{tabular}{|c|c|c|c|c|c|c|c|}
\hline Variable & Field of Study & frequency & Mean & SD & $\mathbf{t}$ & df & sig \\
\hline \multirow{2}{*}{ Social Intelligence } & Related & 7 & $69 / 85$ & $9 / 61$ & \multirow{2}{*}{$-1 / 1$} & \multirow{2}{*}{66} & \multirow{2}{*}{$0 / 274$} \\
\hline & Unrelated & 61 & $73 / 95$ & $9 / 26$ & & & \\
\hline \multirow{2}{*}{ Capability to absorb knowledge } & Related & 7 & 125 & $15 / 34$ & \multirow{2}{*}{$-0 / 387$} & \multirow{2}{*}{66} & \multirow{2}{*}{$0 / 7$} \\
\hline & Unrelated & 61 & $127 / 18$ & $13 / 99$ & & & \\
\hline
\end{tabular}


The findings in Table 7 indicate that regarding social intelligence, administrators majored in education management have a mean value and SD of 69.85 and 9.61, respectively. Administrators majored in unrelated fields have a mean value and $\mathrm{SD}$ of 73.95 and 9.26 , respectively. The findings also show that the calculated $t$ value $(t=1.1, \mathrm{df}=66)$ is not significant at the $95 \%$ level $(p>0.05)$; therefore, it can be concluded that administrators' social intelligence does not vary according to their fields of study.

Considering these findings, regarding capability to absorb knowledge, administrators majored in education management have a mean value and SD of 125 and 15.34, respectively. Administrators majored in unrelated fields have a mean value and SD of 127.18 and 13.99 , respectively. The findings also show that the calculated $t$ value $(t=0.387, d f=$ 66 ) is not significant at the $95 \%$ level ( $p>0.05)$; therefore, it can be concluded that administrators' capability to absorb knowledge does not vary according to their fields of study.

\subsection{Q6: Do administrators' social intelligence and capability to absorb knowledge vary significantly according to their educational level?}

To answer the question, independent t-test was used. The results are presented in Table 8.

Table 8: Results of independent t-test comparing administrators' social intelligence and knowledge absorption capability with regard to their educational level

\begin{tabular}{|c|c|c|c|c|c|c|c|}
\hline Variable & Field of Study & frequency & Mean & SD & $t$ & df & sig \\
\hline \multirow{2}{*}{ Social Intelligence } & $\mathrm{BA}$ & 57 & $73 / 22$ & $9 / 76$ & \multirow{2}{*}{$-0 / 605$} & \multirow{2}{*}{66} & \multirow{2}{*}{$0 / 548$} \\
\hline & MA & 11 & $75 / 09$ & $6 / 62$ & & & \\
\hline \multirow{2}{*}{ Capability to absorb knowledge } & BA & 57 & $127 / 66$ & $14 / 46$ & \multirow{2}{*}{$0 / 95$} & \multirow{2}{*}{66} & \multirow{2}{*}{$0 / 346$} \\
\hline & MA & 11 & $123 / 27$ & $11 / 4$ & & & \\
\hline
\end{tabular}

The findings in Table 8 indicate that regarding social intelligence, administrators with BA have a mean value and SD of 73.22 and 9.76, respectively. Administrators with MA have a mean value and SD of 75.09 and 6.62 , respectively. The findings also show that the calculated $t$ value $(t=6.6, d f=66)$ is not significant at the $95 \%$ level $(p>0.05)$; therefore, it can be concluded that administrators' social intelligence does not vary according to their educational level.

Considering these findings, regarding the capability to absorb knowledge, administrators with BA have a mean value and SD of 127.66 and 14.46, respectively. Administrators with MA have a mean value and SD of 123.27 and 11.4 , respectively. The findings also show that the calculated $t$ value $(t=0.95, \mathrm{df}=66)$ is not significant at the $95 \%$ level $(p>0.05)$; therefore, it can be concluded that administrators' capability to absorb knowledge does not vary according to their educational level.

\section{Discussion and Conclusion}

The results suggested that girls' middle and high schools administrators' social intelligence in Zahedan was above average. The results are consistent with the results of the previously conducted studies carried out by Oslub (2010), Sa'adatmand (2008), Boal \& Hooijberg, (2000), Allahyari (2010), Rezaei and Khalilzadeh (2009), Naderi and Rowshan (2010), Akrami Abarghuyi (2009), Hajizadeh and Naderi (2008), Yahyazadeh, et al (2012), Yahyazadeh and Lotfi Goudarzi (2012), Hampel, et al (2011), Delic, et al. (2011), Deng, et al. (2008) and Riggio and Reichard (2008) that obtained optimal levels of social intelligence.

The results also suggested that girls' middle and high schools administrators' capability to absorb knowledge in Zahedan was above average. The results are consistent with the results of the research by Oslub (2010), Sa'adatmand (2008), Boal and Hooijberg, (2000), Ramezanian and Basaghzadeh (2011), Kotabe et al. (2011), Liao et al. (2010), Che (2009), Deng et al. (2008), Liao et al. (2007), Haro and Domingues (2007), McKelvie et al. (2008), Park, et al (2007), Harrington and Guimaraes, (2005), and Tsai (2001) that obtained optimal levels of capability to absorb knowledge.

There was a significant and direct relationship between administrators' social intelligence and their knowledge absorption capability. This is consistent with Oslub (2010), and Boal and Hooijberg, (2000) who found a significant and direct relationship between administrators' social intelligence and their knowledge absorption capability. Moreover, the findings indicated that there was significant and direct relationship between knowledge absorption capability and components of social skills and social awareness and between social intelligence and components of acquisition, transformation and application. These results are not consistent with the results of Sa'adatmand (2008). 
The results of regression analysis revealed that social information processing and social skills could predict capability to absorb knowledge. In this case, no relevant comparable research background was found.

There was not any significant difference between administrators who had a degree related to education management and administrators had no such education in terms of social intelligence. Administrators' social intelligence did not vary in terms of their field of study. The results are in line with the findings of Oslub (2010) and Sa'adatmand (2008) that showed that social intelligence did not vary in terms of field of study.

Additionally, there was not any significant difference between administrators who had a degree related to education management and administrators with no such education in terms of capability to absorb knowledge. The results are in line with the findings of Oslub (2010) and Sa'adatmand (2008) that showed that capability to absorb knowledge did not vary in terms of field of study.

There was not any significant difference between administrators with MA and administrators with BA in terms of social intelligence and capability to absorb knowledge. The results are in line with the findings of Oslub (2010) and Sa'adatmand (2008) that showed that both social intelligence and capability to absorb knowledge did not vary in terms of field of study.

In this study, the results demonstrated that the correlation between social intelligence and its relationship and knowledge absorption capability was significant. In this regard, it can be stated that social intelligence provided a context for knowledge absorption. Although social intelligence alone is not the main factor which increases the ability to absorb knowledge, but administrators' ability to constructively and helpfully communicate with knowledgeable people needs to have non-cognitive intelligence as a part of social intelligence. According to research studies, non-cognitive intelligence guarantees individuals' success and that if a manager can work continuously in long-term, the reason is not related to his/her high cognitive intelligence, but there are always hermeneutic elements involved.

In addition, the findings revealed that first social information processing and then social skills could predict capability to absorb knowledge. Social intelligence and knowledge absorption capability, the two variables of the study, could be affected by many factors. Here, it was attempted to investigate some of these variables such as educational level and field of study. These two latter variables could not significantly differentiate between administrators.

\section{Recommendations}

According to the results of this study, these recommendations can be provided to improve the performance of administrators:

1. Increasing administrators' social intelligence enhances their ability to absorb knowledge; therefore, holding workshops for administrators in order to increase their social intelligence is recommended.

2. Administrators must act freely regarding their management procedure and they should hold training workshops for teachers where needed. It should be noted that the education system exclusively is allowed to hold such workshops and administrators have to passively anticipate such workshops or in-service courses to absorb knowledge.

3. Encouraging administrators to attend meetings, training courses and reading books.

4. Encouraging administrators to use new materials in order to change organizational behavior and improve activities.

5. Since there is a significant relationship between social skills and the ability to absorb knowledge, administrators who are selected should have high social skills.

\section{Reference}

Akrami Abarghuyi, E. (2009). The relationship between social intelligence and professional maturity in students of Allameh Tabatabai University, MA Thesis, Faculty of Psychology and Educational Sciences. Tehran: Allameh Tabatabai University.

Allahyari, S. (2010). Examining the relationship between social intelligence and moral leadership management training groups at the University of Isfahan and Isfahan University of Medical Sciences, MA Thesis, Faculty of Psychology and Educational Sciences, Isfahan University.

Beheshtifar, M. \& Roasaei, F. (2012). Role of Social Intelligence in Organizational Leadership, European Journal of Social Sciences, 28(2), 197-203.

Beikzadeh, J. \& Dodemani Maleki, H. (2011). Effect of organizational factors on knowledge management in education: a case study of education of Malekan, Quarterly of Informative Research and Public Library, 17(4), 649-675.

Boal, K.B. \& Hooijberg, R. (2000), Strategic Leadership Management, the Leadership Quarterly, 11(4), 515- 549.

Che, Y.S., Lin, M.J., \& Chang. (2009). The Positive Effects of Relationship Learning and Absorptive Capacity on Innovation Performance 
and Competitive Advantage in Industrial Markets, Industrial Marketing Management, 38, 152- 158.

Comison, C. \& Fores, B. (2010). Knowledge absorptive capacity: New insights for its conceptualization and measurement, Journal of Business Research, 63, 707-715.

Delic, L., Novak, P., Kovacic, J. \& Avsec, A. (2011). Self-reported Emotional and Social Intelligence and Empathy as Distinctive Predictors of Narcissism, Psychological Topics, 20 (3), 477-488.

Deng, X. Doll, W.J., \& Cao, M. (2008). Exploring the absorptive capacity to innovation/productivity link for individual engaged in IT enabled work, information \& management, 45(2), 75- 87.

Gini, G. (2006), Brief report: Adaptation of the Italian Version of the Tromsø Social Intelligence Scale to the adolescent population, Journal of Adolescence, 29(2), 307-312.

Golman, D. (2009). Social intelligence. Translated by: Razmara, H. Tehran: Sepanj Publication.

Hajizade, M. \& Naderi, F. (2008). Validation scale of social intelligence and its relation to happiness and aggression among students of Islamic Azad University of Ahvaz, MA Thesis, Department of General Psychology, Islamic Azad University of Ahvaz.

Hampel, S. Weis, S., Hiller, W., \& Witthöft, M. (2011). The relations between social anxiety and social intelligence: A latent variable analysis, Journal of Anxiety Disorders, 25, 545-553.

Haro-Dominguez, Ma del Carmen. Arias-Aranda, Daniel. Javier L loréns- Montes, Francisco. Ruíz Moreno, A. (2007). The impact of absorptive capacity on technological acquisitions engineering consulting companies, Technovation, 27(8), 417-425.

Harrington, S.J. \& Guimaraes, T. (2005). Corporate Culture, Absorptive capacity and IT Success, Information and Organization, 15, 3963.

Hooda, D., Rattan, Sh. N., \& Yadava. A. (2009), Social Intelligence as a Predictor of Positive Psychological Health, Journal of the Indian Academy of Applied Psychology January, 35(1), 143-150.

Kihlstrom, J. F. (2000), Social Intelligence; Hand Book of intelligence, Cambridge, U.K.: Cambridge University Press, 395- 379.

Kotabe, M., Xiangwen, J., Crystal, M., Janet, Y. (2011), Managerial ties, knowledge acquisition, realized absorptive capacity and new product market performance of emerging multinational companies: A case of China. Journal of World Business, 46, 166-176.

Lenox, M. \& King, A. (2004). Prospects for Developing Absorptive Capacity through Internal Information Provision, Strategic Management Journal, 25(4), 331- 345.

Liao, S.H., Fei, W. N., \& Chen C. C. (2007). Knowledge Sharing, Absorptive Capacity and Innovation Capability, Journal of Information Science, 33(3), 340-356.

Liao, Sh. H. W., Chi-Chuan. H., Da-Chian. T., \& Guang A. (2010). Knowledge Acquisition, Absorptive Capacity, and Innovation Capability: An Empirical Study of Taiwan's Knowledge-Intensive Industries, International Journal of Human and Social Sciences, 5(12), 759-766.

Luqmannia, M. \& Khamesan, A. (2010). The position of national identity in the education system, Journal of Cultural Research, 3(2), $147-171$.

McKelvie, A. Wiklund, J. \& Short, J.C. (2008). The New Venture Innovation Process: Examining the Role of Absorptive Capacity, Entrepreneurial Strategic Processes. (Advances in Entrepreneurship, Firm Emergence and Growth), 10, 159-185.

Mirkamali, S.M. (2007). Leadership and Education Management. Second Edition, Tehran: Yastaron Publication.

Murovec, N. \& Prodan, I. (2009), Absorptive capacity, its determinants, and influence on innovation output: Cross-cultural validation of the structural model. Technovation, 29, 859-872.

Naderi, F. \& Rooshani, Kh. (2010). The relationship between spiritual and social intelligence with death anxiety in older women, Women and Culture Research Journal, 2(6), 55-67.

Oslub, S. (2010). Examining the relationship between social intelligence and ability to absorb knowledge among city managers in Bukan, MA Thesis, Department of Educational Sciences and Psychology, University of Isfahan.

Park, J.H. Suh, H.J. Yang, H.D. (2007). Perceived Absorptive Capacity of Individual Users in Performance of Enterprise Resource Planning (ERP), Information and Management; 44(3), 300-312.

Rahmani, Z. \& Mousavi, S.A. (2011), Enhancing the Innovation Outcomes of Absorptive Capacity in the Organization: A Conceptual Framework. International Journal of Innovation Management and Technology; 2 (5), 430-435.

Ramezanian, M.R. \& Basaghzadeh, N. (2011). The effect of ability to absorb and organizational culture on IS success in auto parts manufacturing companies in Gilan, Information Technology Management, 3(9), 41-68.

Rezaei, A. \& Khalilzadeh, A. (2009). The relationship between social intelligence and job satisfaction among school teachers, Educational Sciences, 2(7), 121-145.

Rezaei, A. (2010). Tromso's social intelligence scale: Factor structure and reliability of the Persian version of the scale among students' population, Tabriz Journal of Psychology Research, Tabriz, 5(20), 70-87.

Riggio, R. \& Reichard. R. (2008). The emotional and social intelligences of effective leadership, Journal of Managerial Psychology, 23(2), 169-185.

Sa'adatmand, M. (2008). Investigating the relationship between social intelligence and ability to absorb knowledge among girls' high schools managers in Mashhad, MA Thesis, Department of Educational Sciences and Psychology, Ferdowsi University of Mashhad.

Safi, A. (2001). Organization and administration of schools. Third Edition. Tehran: The Growth Publication.

Shaker, Z. \& Gerard, G. (2002). Absorptive capacity: A Review Reconceptualization and tension, Academy of management Review; 27(2), 185- 203.

Sobhaninejad, M. (2006). LO: Theoretical Foundations of research and evaluation model. Tehran: Yastaron publication. 
Tsai, W. (2001). Knowledge transfer in intra-organizational networks: Effects of network position and absorptive capacity on business unit innovation and performance, Academy of Management Journal, 44(5), 996-1004.

Uotila, T. (2006). A method for Assessing Absorptive capacity of regional innovation system, Fennia, 184(1), 49-58.

Yahyazadeh J.S., Suraya Md Yunus, A. Roslan, S. Md. Nor.SH. (2012). The Influence of Social Intelligence of Secondary School Teachers on Classroom Discipline Strategies, J Psychology, 3(1), 39-4542.

Yahyazadeh, J.S. \& Lotfi- Goodarzi, F. (2012). Predicting Senior Secondary Schools Teachers' Social Intelligence by HEXACO-PI-R personality Traits based on Age Groups, International Journal of Asian Social Science, 2(5), 739-747. 